Int. J. Dev. Biol. 62: 109-119 (2018)

https://doi.org/10.1387/ijdb.170325ct

\title{
Chick midgut morphogenesis
}

\author{
TYLER R. HUYCKE and CLIFFORD J. TABIN* \\ Department of Genetics, Harvard Medical School, Boston, MA, USA
}

\begin{abstract}
The gastrointestinal tract is an essential system of organs required for nutrient absorption. As a simple tube early in development, the primitive gut is patterned along its anteriorposterior axis into discrete compartments with unique morphologies relevant to their functions in the digestive process. These morphologies are acquired gradually through development as the gut is patterned by tissue interactions, both molecular and mechanical in nature, involving all three germ layers. With a focus on midgut morphogenesis, we review work in the chick embryo demonstrating how these molecular signals and mechanical forces sculpt the developing gut tube into its mature form. In particular, we highlight two mechanisms by which the midgut increases its absorptive surface area: looping and villification. Additionally, we review the differentiation and patterning of the intestinal mesoderm into the layers of smooth muscle that mechanically drive peristalsis and the villification process itself. Where relevant, we discuss the mechanisms of chick midgut morphogenesis in the context of experimental data from other model systems.
\end{abstract}

KEY WORDS: intestine morphogenesis, gut looping, villus formation, smooth muscle, biomechanics

\section{Introduction}

The gastrointestinal (GI) tract is an essential system of organs that perform functions vital to nutrient absorption. Throughout embryogenesis, molecular signals and mechanical forces sculpt the gut through a series of complex morphogenetic events that give rise to its adult form in a process that is largely conserved across species. The distinct Gl organs derive from a common primitive gut tube. In a classic study, Caspar Friedrich Wolff observed the early morphogenesis of the chick gut as it transformed from a sheet into a tube, considering it a prime example of epigenesis - the prevailing hypothesis that adult form develops progressively through stepwise morphological transformations during embryogenesis (Wolff and Dupont, 1768-1769). This transformation is accomplished early in development via morphogenetic cellular movements at two ventral invaginations of the endoderm at the opposite ends of the embryo, the anterior and caudal intestinal portals. These events culminate in the fusion of the endoderm into the primitive gut tube at approximately day 3 of embryonic development in the chick (Le Guen et al., 2015, McLin et al., 2009, Roberts, 2000, Spence et al., 2011). At this point, the gut exists as a simple composite tube composed of an endodermal epithelium ensheathed in mesenchyme recruited from the splanchnic portion of the lateral plate mesoderm and is suspended from the abdominal wall through the dorsal mesentery. Soon after its formation, the gut is colonized in an anterior to posterior wave by neural crest cells derived from the ectoderm. Thus, the development and function of the digestive tract is ultimately the result of molecular and mechanical interactions between all three germ layers.

Reciprocal signaling between the epithelium and mesenchyme regionalize the gut along its anterior-posterior axis. Heterologous tissue recombination experiments between these layers demonstrate the importance of cross-talk between the two tissues. This interactive process is highlighted by the fact that both the endoderm and mesoderm exhibit instructive effects on the induction of cell fate and morphology of the other with spatial and temporal dependence. Cross-talk between the tissues continues throughout development and into adult life, playing important roles in patterning and stem cell maintenance and contributing to epithelial differentiation. These interactions have been reviewed in detail elsewhere (Chin et al., 2017, Crosnier et al., 2006, de Santa Barbara et al., 2003, Le Guen et al., 2015, McLin et al., 2009, Noah et al., 2011, Roberts, 2000, Roberts et al., 1998, Spence et al., 2011, Wells and Spence, 2014, Yasugi and Mizuno, 2008).

With regard to form, the overall output of these molecular interactions resolves with the partitioning of the digestive tract into discrete compartments that are morphologically apparent at day 3

\footnotetext{
Abbreviations used in this paper: BMP, bone morphogenetic protein; CAM, chorioallantoic membrane; DM, dorsal mesentery; ECM, extracellular matrix; ENS, enteric nervous system; GI, gastrointestinal; Hh, Hedgehog; ICG, interstitial cells of Cajal; SMC, smooth muscle cell.
} *Address correspondence to: Clifford J. Tabin. 77 Avenue Louis Pasteur, Harvard Medical School, Department of Genetics, NRB Rm 360, Boston, MA 02115, USA.
Fax: +1-(617) 432-7595. Tel: +1-(617) 432-7618. e-mail: tabin@ genetics.med.harvard.edu - (D) http://orcid.org/0000-0002-2957-4871 
of chick development: the foregut, midgut, and hindgut (Romanoff, 1960). In terms of the avian digestive tract, the foregut gives rise to the esophagus, crop, gizzard, and proventriculus or glandular stomach; the midgut to the small intestine; and the hindgut to the large intestine. At the boundary of the small and large intestine are the ceca, two blind ended sacs continuous with the gut lumen that are analogous to the mammalian appendix. Each compartment is specified to develop unique morphologies that are required for their specific functions in the digestive process. For example, the midgut drastically increases its absorptive surface area via two modes: elongation and villification. At the same time, the gut mesenchyme is patterned along its radial axis into distinct layers of smooth muscle and neurons that mediate the contractions of these muscles to drive coordinated peristalsis. This review highlights work in the avian embryo that has contributed to our knowledge of how physical forces and molecular cues are integrated to drive these processes that pattern and shape the functional digestive tract.

\section{Looping morphogenesis}

\section{Intestinal rotation}

The human small intestine is approximately 20 feet long yet must be packaged to fit within the tight space constraints of the body cavity - a problem accomplished through a looping process initiated early in development. As midgut elongation outpaces axial elongation of the embryo, it is forced into a hairpin loop that buckles ventrally into a space outside of the abdominal wall (within the yolk stalk in birds, the umbilicus in mammals) at approximately embryonic day 5 in the chick (Davis et al., 2008, Soffers et al., 2015). As it does so it initiates a 90 degree counterclockwise turn. In subsequent days the gut undergoes an additional 180 degree counterclockwise rotation before it is retracted back into the body cavity late in development (just prior to hatching) (Davis et al., 2008, Soffers et al., 2015, Southwell, 2006).

This looping process occurs in a highly stereotyped manner that initiates with a critical leftward tilt in the gut early in development. That the midgut itself displays radial symmetry in cross section begs the question of how the chirality of this looping process is established. As the endoderm fuses into a tube, the endoderm recruits splanchnic mesoderm from the lateral plate (Roberts, 2000).
A portion of this mesoderm becomes the dorsal mesentery (DM), eventually a thin, elastic membrane, but initially a stiff block of tissue composed of mesenchyme situated between two epithelia. This DM is attached along the dorsal edge of the midgut, suspending it within the coelom (Davis et al., 2008). Between HH20-22 a symmetry breaking event occurs in which cells of the right half of the DM mesenchyme become more dispersed, while cells of the left mesenchyme compact (Fig. 1). Concomitantly, the right epithelium flattens, elongating the tissue, while the cells of the left retain a narrow columnar morphology (Davis et al., 2008, Kurpios et al., 2008). These cellular changes transform the dorsal mesentery at its point of attachment to the gut from rectangular into trapezoidal cross-sectional geometry that tilts the gut tube leftward. These cellular asymmetries are driven by the same molecular cues that guide early left/right (L/R) patterning of the embryo. Pitx2, a gene downstream of the left side patterning signal Nodal, is expressed at the onset of asymmetries exclusively on the left side of the DM, where it initiates a positive feedback loop with another transcription factor, Isl1, and drives the expression of $\mathrm{N}$-cadherin (Fig.1). $\mathrm{N}$-cadherin in turn directs the adhesion of cells on the left side that leads to their condensation and increased density. This is reinforced by asymmetric secretion of extracellular matrix components, acidic glycosaminoglycans on the left and hyaluronic acid on the right. Misexpression of these genes leads to a loss of asymmetry and any minimal tilting that still occurs becomes randomized in orientation (Davis et al., 2008, Ryan et al., 1998).

These events are further orchestrated through interactions with additional signaling pathways. Expression analysis of left and right DM at the time of leftward tilt revealed an enrichment of Wnt pathway genes on the left and Wnt inhibitors on the right (Welsh et al., 2013). The formin Daam2, an intracellular effector of Wnt and a target of Pitx2 is expressed on the left and is necessary and sufficient to drive the compaction of mesenchymal cells. Daam2 function is likely mediated by asymmetric activity of Wnt5a (derived from the adjacent mesoderm of the gut tube) in conjunction with its receptors Fzd4/8 on the left side of the DM (Welsh et al., 2013). Together, these data suggest a mechanism whereby the canonical L/R signaling pathway establishes cellular differences within the DM that are further potentiated by noncanonical Wnt signaling. In addition to generating morphological changes, Pitx2
HH19
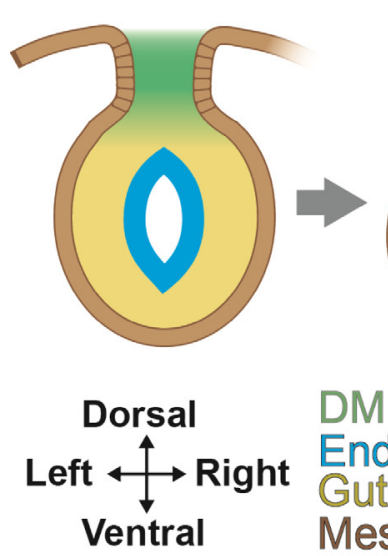

HH20-22
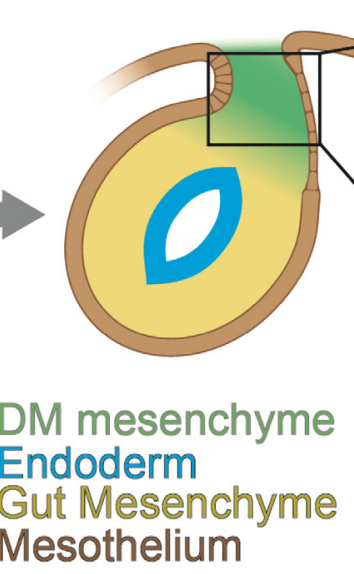
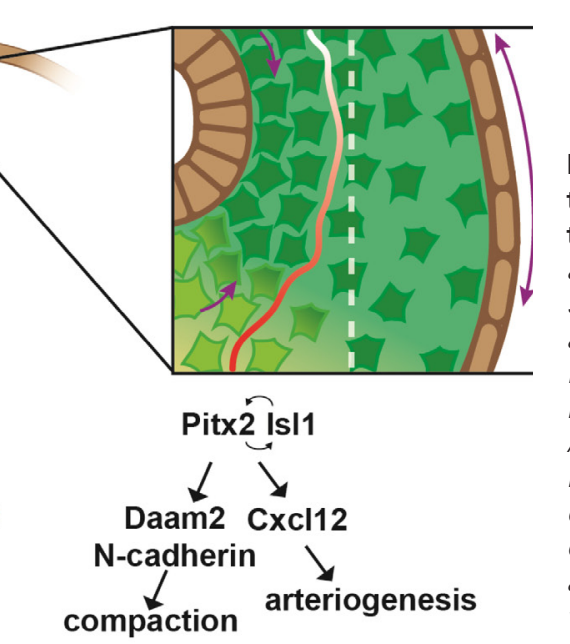

Fig. 1. Establishment of asymmetry in the gut tube. Representations of transverse cross sections through the early gut tube. Asymmetries arise in the dorsal mesentery (DM) between $\mathrm{HH}$ stage 20-22. Left side specific Pitx2 expression activates Daam2 and, through Is/1, also activates $\mathrm{N}$-cadherin, which interacts with Daam2 to drive mesenchymal cell compaction within the left DM. Additionally, Pitx2/Is/1 drives columnar epithelial morphology on the left side of the DM, while epithelial cells on the right flatten. Together, these cellular asymmetries drive leftward tilting. Pitx2 also activates Cxcl12 to drive arteriogenesis (red) within the left DM. 
acting through its downstream target Cxcl12 initiates the formation of arteries and lymphatics (themselves dependent upon the formation of the arteries) specifically on the left side of the DM (Mahadevan et al., 2014) (Fig. 1).

Recent work in Xenopus has shown similar asymmetries arise within the gut tube itself, manifesting as condensations and expansions of mesenchyme and reorganization of epithelia on the left and right sides of the developing stomach that drive its curvature (Davis et al., 2017). Perhaps not surprisingly these asymmetries are also driven by asymmetrical expression of $L / R$ pathway genes. Thus, not only does Pitx2 invoke asymmetries in the mesentery, causing a non-autonomous effect on gut looping, but depending on the region of the gut, also acts within the primitive gut tube itself to generate curvature. Another example of asymmetry within the gut tube is the duodenojejunal flexure (DJF), which is a stereotyped curvature at the point that separates the duodenum from the jejunum. In mice, similar mesenchymal and epithelial changes are seen here that seem to drive the curvature independently of the dorsal mesentery (Onouchi et al., 2016, Onouchi et al., 2015). However, whereas differential proliferation does not seem to be present in the DM or curving stomach, it does seem to be a driving force for DJF formation as the outer curvature shows increased cell divisions that create a bend in the gut tube (Onouchi et al., 2013). Whether Pitx2-mediated sculpting of the stomach or other organs is at play in the chick is currently unknown.

\section{Formation of intestinal loops}

Besides the rotations initiated by asymmetries within the DM described above, the small intestine must form progressively more loops as it elongates for it to accommodate its extensive length within the coelom (Fig. 2). Dissection of the small intestine and DM away from all other embryonic tissues maintains the looping morphology, indicating that the forces governing the process are intrinsic to these two tissues. In contrast, separating the gut from mesentery causes the gut to uncoil and the mesentery to recoil. These simple yet informative experiments demonstrate that the gut tube is under compression while the mesentery is under tension (Savin et al., 2011). In essence, although the two tissues are continually attached to one another along their length, separation reveals that the DM is significantly shorter in its released side than is the gut tube, a difference established via differential growth. Mathematical and computational modeling provide strong evidence that looping morphogenesis is dependent upon this differential growth between the faster growing midgut and slower growing DM. In conjunction, the specific tissue geometries and stiffnesses here cause the midgut to buckle into a precise looping pattern (Savin et al., 2011).

Ultimately regulating the mechanical buckling process of intestinal looping are molecular signals that define growth rates as well as geometric and physical properties of the intestine and DM. Prior to and during the looping process, Bmp2 is expressed

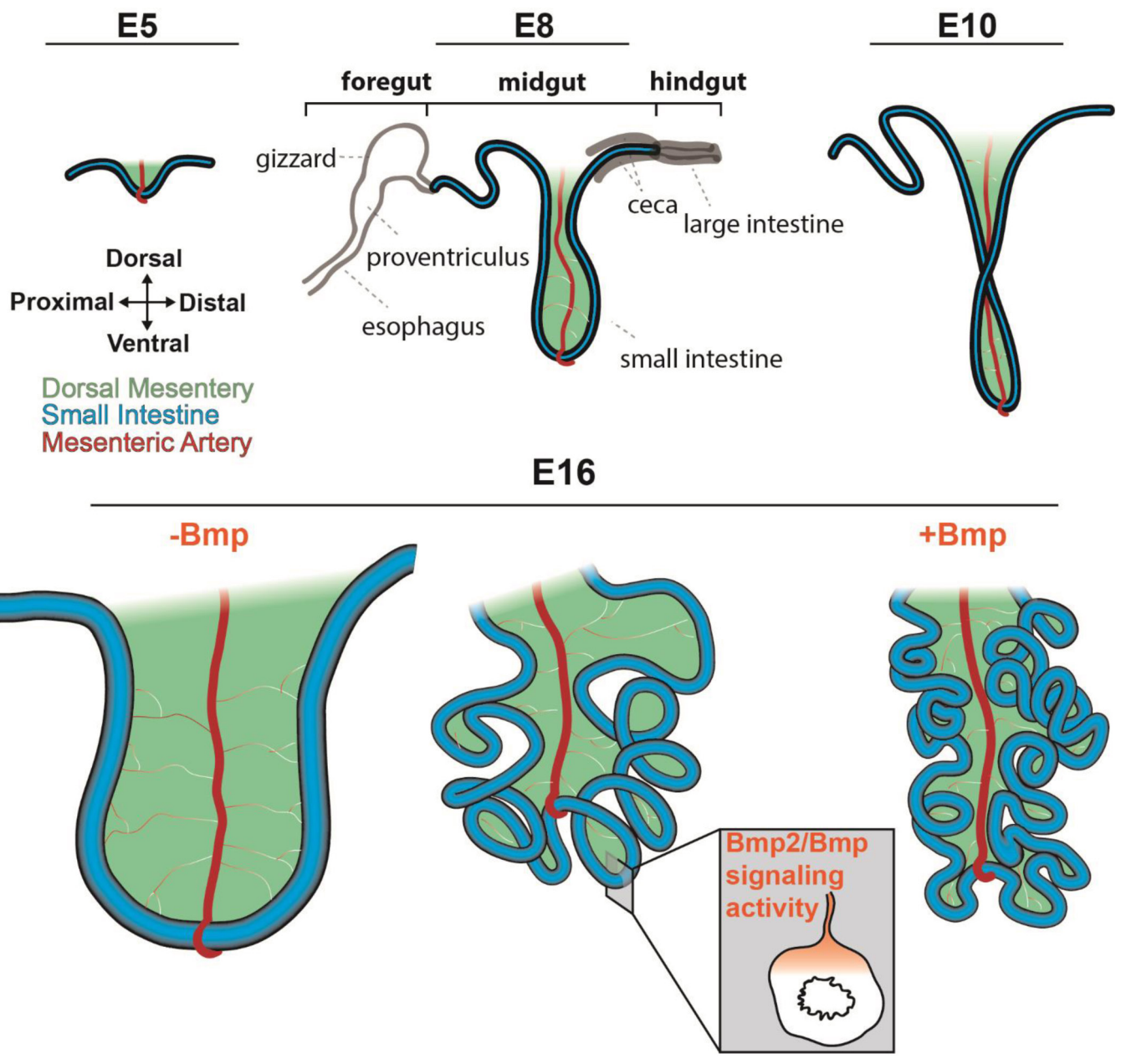

Fig. 2. Looping morphogenesis of the midgut. At embryonic day 5 (E5), the midgut (blue) forms a hairpin loop that buckles ventrally at the attachment of the superior mesentericartery (red). This hairpin loop increases in length during development, and by E10 turns counterclockwise 90 degrees. At E16, the midgut displays a highly stereotyped looping morphology caused by differential growth between the dorsal mesentery and the faster growing gut tube that leads to tissue buckling. Bmp signaling activity, which is present in a dorsal to ventral gradient from the dorsal mesentery to the intestinal mesenchyme, regulates this differential growth: hyperactivation using RCAS-Bmp2 (+Bmp) increases loops, while inhibition using RCAS-Noggin (-Bmp) reduces looping. Other compartments of the digestive tract are shown in grey at E8 for context. 
in a dorsal to ventral gradient throughout the mesoderm from the mesentery through the dorsal gut tube, matching a gradient of Bmp signaling activity (Lyons et al., 1990, Nerurkar et al., 2017) (Fig. 2). Misexpression of Bmp2 results in a shorter mesentery and increased number of loops, whereas misexpression of the Bmp inhibitor Noggin leads to a longer mesentery and decrease in number of loops. In both these scenarios, the length of the gut tube is unaltered, yet with Noggin misexpression the tube increases in diameter, bringing up the possibility that growth across the different axes can be genetically uncoupled (Fig. 2). Thus, Bmp signaling modulates looping morphogenesis by controlling differential growth between elongation rates in the gut tube and mesentery (Nerurkar et al., 2017).

The tissue scale forces generated through the process were mathematically and computationally modeled to demonstrate that differential growth between the DM and midgut along with the experimentally measured tissue stiffnesses and geometries can sufficiently explain the looping process, which itself is highly stereotyped within a given species. In fact, the model generated and first verified using experimental data from the chick can account for the looping morphologies seen in other species (Savin et al., 2011). In the finch midgut, which has fewer loops than that of the chick, Bmp activity levels are decreased in the DM, raising the intriguing possibility that the Bmp signaling pathway may be modulated across evolution in avian species to generate unique looping morphologies (Mitchell, 1896, Nerurkar et al., 2017).

\section{Villification}

Following compartmentalization and concomitant with the looping process, the luminal surface of the avian small intestine undergoes a series of structural changes that sequentially transform the initially flat epithelium into a series of ridges, zigzags, and eventually villi (Burgess, 1975, Coulombre and Coulombre, 1958, Grey, 1972, Hilton, 1902). Drawing upon the ideas of D'Arcy Thompson, Coulombre and Coulombre (1958) originally proposed a mechanical basis for these geometrical changes whereby smooth muscle layers within the mesoderm constrain the growth of the inner layers (undifferentiated mesenchyme and endoderm), causing them to buckle. Recent work in the chick combining experimental data with mathematical modeling has provided strong evidence toward this hypothesis (Ben Amar and Jia, 2013, Shyer et al., 2013). Coincident with each of the steps outlined above (longitudinal ridges to zigzags to villi), layers of smooth muscle cells (SMCs) differentiate within the mesoderm in a stepwise manner (Fig. 3). At approximately embryonic day (E6) in the chick, the first layer of circular smooth muscle differentiates, constraining growth circumferentially and causing the epithelium and underlying mesenchyme to buckle into longitudinal ridges that run down the length of the small intestine. Next, at E12 an outer layer of longitudinally aligned smooth muscle differentiates between the circumferential layer and the mesothelium, providing longitudinal constraint such that, with further growth, the ridges are compressed into zigzags. The final step of epithelial transformation is the formation of villi, which is directed by the differentiation of a third inner layer of longitudinally oriented smooth muscle at E16, which in itself tightens the folds of the ridges, combined with a shift in proliferation pattern to the base of the folds (Fig. 3). The fact that inhibition of muscle differentiation prevents each transformative step, and artificially constrained growth within silk tubes to mimic the smooth muscle function leads to buckling morphogenesis argues that this process is purely driven by physical means. In further support of this, mathematical and computational modeling of experimentally measured physical parameters can recapitulate the buckling morphogenesis observed in vivo in the chick and other species (Shyer et al., 2013). How these mechanisms of differential and constrained growth are varied along the length of the digestive tract to contribute to compartment specific luminal folding patterns is an open question, but the fact that the general smooth muscle organization is similar across the length of the digestive tract, but the thickness of the different layers vary, suggests variation of this general mechanism may modulate luminal topography, as has recently been shown in the epithelial buckling of the oviduct (Koyama et al., 2016) (Lim and Low, 1988, Yamamoto et al., 1996).

The villi that form through these biomechanical processes are significantly shorter than the mature villi of the adult intestine where it is known that stem cell differentiation plays a key role in the maintenance of villus structure. Still, it remains to be determined whether physical forces also play a role in the continued outgrowth of villi throughout later development and postnatal life.

\section{Mechanical influence on signaling and stem cells}

During early gut development, proliferating cells are found uniformly throughout the epithelium, however they gradually become restricted to the intervillus spaces and eventually crypts as the epithelium buckles (Crosnier et al., 2006, Overton and Shoup, 1964, Shyer et al., 2015). Driving the localization of these proliferating cells are the morphological changes that arise during villification. Deformation of the epithelium and mesenchyme alters the spatial distribution of morphogen gradients within the tissue, thereby affecting molecular events in emerging villi. In particular, there is a gradient of Sonic Hedgehog (Shh) emanating from the endoderm and diffusing through the mesenchyme (Fig. 3). Visualization of this gradient demonstrates that as the zig-zag ridges become tightly constrained as the inner layer of smooth muscle differentiations, the concentration of Shh becomes elevated specifically at the tips of nascent villi. This leads to threshold concentrations of Shh that can activate downstream targets such as Bmp2, Bmp4, and Pdgfra at high levels specifically in the mesenchyme at villus tips (Shyer et al., 2015), in domains known as villus clusters (Karlsson et al., 2000). Subsequently, Bmp signaling reciprocally feeds back to the endoderm and locally inhibits Wnt signaling and proliferation (through a currently unknown mechanism), thereby blocking proliferation at the tips of emerging villi (Fig. 3). Importantly, the concentration of signals is not stage dependent, but shape dependent, as removing the tight folding at late stages results in a loss of morphogen localization and subsequently maintenance of uniform proliferation. Conversely, the formation of artificial villi at early stages localizes Hedgehog signaling and creates villus clusters at a time prior to when they normally appear, indicating that tissue shape alone can distort a morphogen gradient to localize signal and initiate expression of target genes.

The proliferative compartment of the adult intestinal epithelium is within the intestinal crypts, the invaginations into the mesenchyme between villi where Lgr5 positive stem cells divide during normal homeostasis to give rise to all cell types of the epithelium (Barker et al., 2007). Mirroring the restriction of proliferating cells to the intervillus space, Lgr5 expression is also gradually restricted in the 
same way. Based on lineage tracing experiments in mice, it seems that at least some of these embryonic Lgr5-expressing cells give rise to the bona fide adult intestinal stem cells that are located in crypts (Barker et al., 2007, Shyer et al., 2015). Thus, the distortion of the Shh morphogen gradient by tissue shape changes leads to the localization of a proliferative compartment of cells within the intestinal epithelium that presumptively gives rise to the stem cell compartment (Fig. 3). The factors regulating the formation of crypts themselves have yet to be elucidated, although since crypt

\section{E5-7}
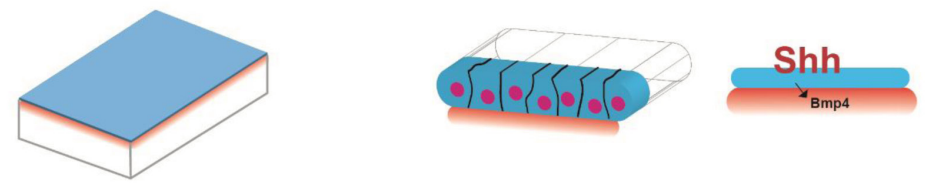

\section{E8-12}

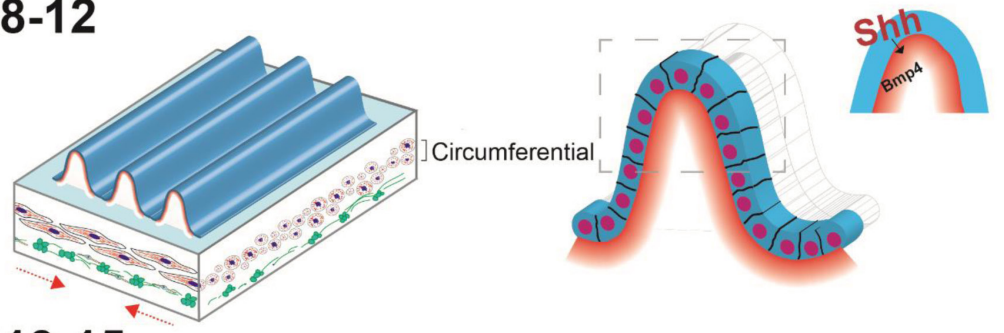

E13-15

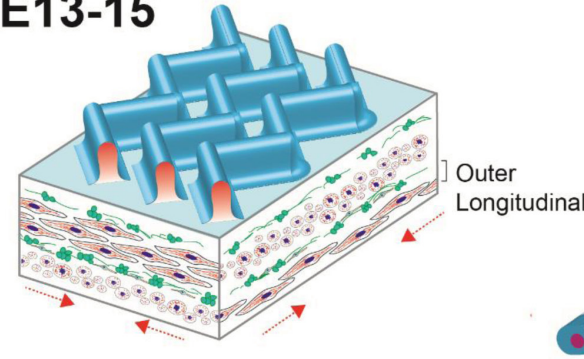

E16-
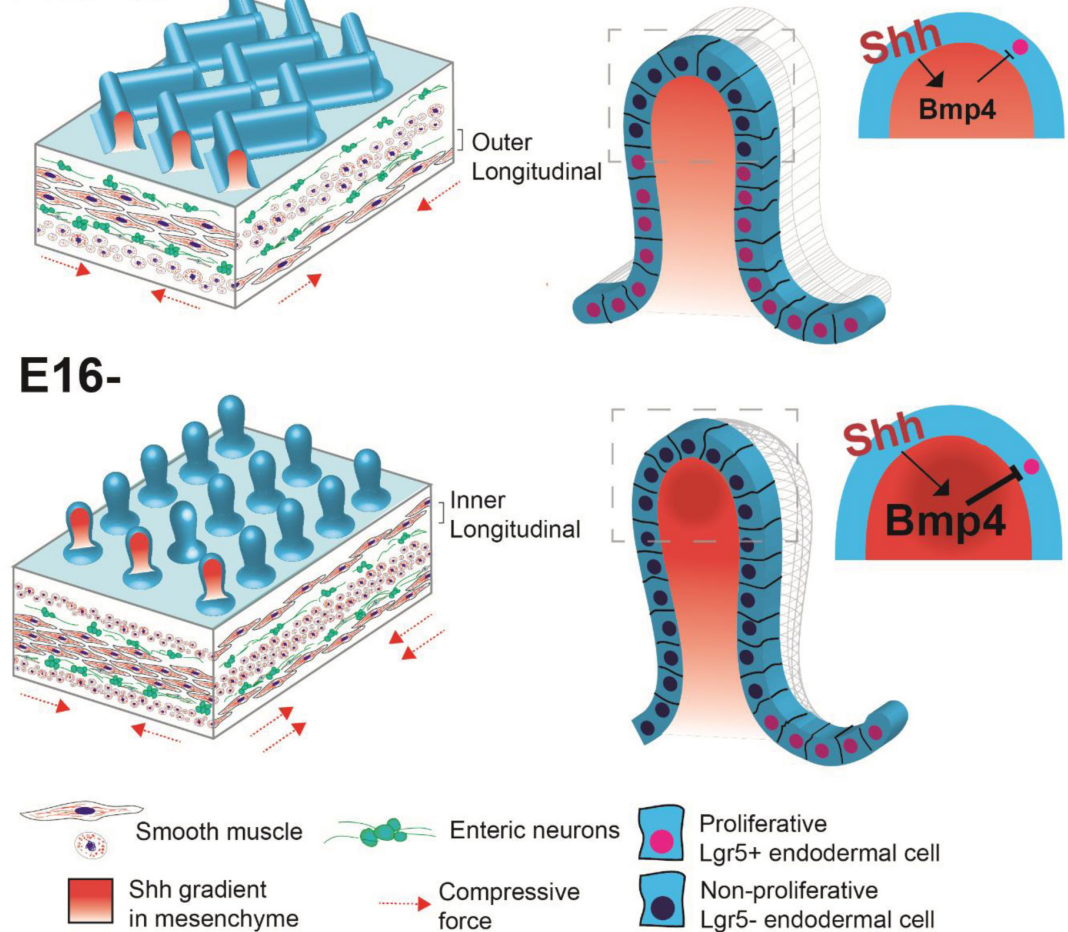

Proliferative Lgr5+ endodermal cell Non-proliferative Lgr5- endodermal cell

Fig. 3. Villification and intestinal stem cell localization. Cross-sectional illustrations of the small intestine demonstrating sequential transformation of the intestinal epithelium from a flat surface (E4-7), to longitudinal ridges (E8-12), to zigzags (E13-15), and finally to villi (E16-adult) as it coincides with progressive layers of aligned smooth muscle that differentiate within the mesoderm. Panels on right show close up views of the folds at each time point demonstrating how Shh, which is expressed by the epithelium, becomes focally localized within the mesenchyme at the tips of the folds to drive the high expression of villus cluster genes such as Bmp4, which in turn signals back to the epithelium to inhibit proliferation/stem cell identity. formation happens in organoids that lack smooth muscle layers (Clevers, 2013) it is unlikely the same physical forces that form villi are at play here. directly out of the flat epithelium (Hilton, 1902, Sbarbati, 1982). An naling based model has been proposed in the mouse that is dependent upon a Turing-like mechanism. This model also involves Bmp signaling, but places it upstream in establishing Hedgehog-dependent clusters of mesenchymal cells at defined intervals throughout the mesoderm - each marking where a villus will form (Walton et al., 2012, Walton et al., 2016b). Cluster formation occurs concomitantly with basal deformations of the endoderm which is subsequently mirrored by apical bulges that resolve into nascent villi (Karlsson et al., 2000, Walton et al., 2016b). This sequence is opposed to the chick, where cluster formation occurs following epithelial deformation (Shyer et al., 2015). The key differences have recently been reviewed (Walton et al., 2016a). One important difference in the mouse is that the endoderm is only 1.5 times as stiff as the mesenchyme (as opposed to 10 times stiffer in the chick) - a critical value in the simulation of mouse villification (Shyer et al., 2013). Additional modeling approaches have demonstrated that various patterns of epithelial buckling reminiscent of mouse villification can be generated by physical parameters given particular endoderm/mesenchyme stiffness, geometric, and elastic properties (Balbi and Ciarletta, 2013, Balbi et al., 2015, Ciarletta et al., 2014, Shyer et al., 2013). Interestingly, knockout of laminin $\alpha 5$ in mice results in the formation of longitudinal ridges, although it's not clear if these arise during development or through the division of villi later (Mahoney et al., 2008). While blockade of smooth muscle differentiation in the mouse also results in a lack of villi (Shyer et al., 2013), determining whether cluster formation is also driven by smooth muscle will be important in reconciling the two mechanisms. To gain further insight into these species-specific patterns and address the nature of these differences of how villi emerge, it may be worthwhile to revisit hetero- and homochronic recombinants of mouse endoderm with chick mesenchyme and vice versa. Indeed, it has been previously shown that rat fibroblasts can induce ridge and zigzag morphology when recombined with chick endoderm, suggesting that the physical properties of the endoderm may govern how it buckles (Haffen et al., 1982). Given that the pace of muscle formation is faster in the mouse than in the chick, which presumably lends to the lack of transitional geometries, it will be interesting to see if blocking differentiation of the longitudinal layer, and thus allowing growth without longitudinal compression, will result in the formation of ridges on the mouse endoderm. Moreover, it will be important to resolve these differences since mecha- 
nisms of villi formation similar to both chick and mouse may be at play during human intestinal development. For example, transient formation of ridges have been reported in the developing large intestine and proximal small intestine, whereas the distal portions of the gut display more of a mouse-like morphogenic process (Bell and Williams, 1982, Johnson, 1910, Johnson, 1913, Johnson, 1914, Lacroix et al., 1984).

\section{Development of intestinal smooth muscle}

As discussed above, the sequential differentiation of the distinct smooth muscle layers in the chick midgut are critical for the mechanically-based formation of intestinal villi in the chick, in addition to their essential role in peristaltic contractions required for the breakdown and transit of food through the gut. The onset of smooth muscle differentiation involves activation of $\alpha$-smooth muscle actin ( $\alpha S M A)$ expression, whereas mature SMCs express $\gamma$ SMA and contractile markers such as Calponin (Gabella, 2002, McHugh, 1995, McKey et al., 2016). Using $\alpha$ SMA as a marker, the three layers of smooth muscle can be seen to differentiate sequentially from the splanchnic mesoderm and display highly-specific cellular alignments imperative to their function (Fig. 3). The first sign of muscle differentiation occurs at approximately E4 in the chick when mesenchymal cells begin to align in a circumferential orientation, standing out from the seemingly disordered mesenchyme. This is followed by the onset of $\alpha$ SMA expression as the first layer of circumferentially aligned muscle resolves by E6 (Gabella, 2002). Over subsequent days, an outer longitudinal layer develops at E12 and an inner longitudinal layer at E15. This general architecture of inner circular and outer longitudinal muscle is conserved across species with the exception that the inner longitudinal layer is much thicker in the chick than its counterpart, the muscularis mucosae, in the mouse (Kedinger et al., 1990, McHugh, 1995, Wallace et al., 2005). In the avian intestine, the circumferential layer of muscle can further be subdivided into an inner layer that stains highly for $\alpha$ SMA and a thicker outer layer that has low $\alpha$ SMA expression (Gabella, 2002, Thomason et al., 2012, Yamamoto et al., 1996). While it was classically believed that muscle differentiation proceeds in a proximal-to-distal wave, recent analysis re-evaluates this hypothesis and suggests that a concurrent distal-to-proximal wave of differentiation initiates in the hindgut (Bourret et al., 2017, Graham et al., 2017). Despite the difference in timing, the general pattern of muscle layers is conserved along the length of the gut.

Initial patterning and differentiation of smooth muscle depends on the Hedgehog ligands Sonic (Shh) and Indian Hedgehog (Ihh) that signal in a paracrine fashion from the endoderm to generate radial pattern within the mesoderm. Tissue recombination studies in the chick suggest that Shh acts to inhibit smooth muscle differentiation, as cells closest to the Shh source fail to differentiate into smooth muscle (Sukegawa et al., 2000). In contrast, genetic studies in mice suggest that Hedgehog is a positive regulator of smooth muscle: mice lacking endodermal Shh and Ihh expression show a lack of smooth muscle differentiation, whereas mice with hyperactive hedgehog signaling have an increase in smooth muscle (Mao et al., 2010, Ramalho-Santos et al., 2000). Furthermore, both in vivo and in vitro data suggests Hh signaling elicits a positive effect on smooth muscle differentiation in a direct manner, independent of its downstream target BMP (Zacharias et al., 2011).

A second signaling system that has been implicated in smooth muscle differentiation is the Bmp pathway. In the midgut, Hh signaling activates Bmp4 in a subepithelial mesenchymal population of cells that do not differentiate into smooth muscle (Narita et al., 1998, Roberts et al., 1995, Roberts et al., 1998, Sukegawa et al., 2000). In contrast, early gizzard mesenchyme, characterized by a thick smooth muscle layer, does not express Bmp4 early on, and misexpression of Bmp4 or activation of the Bmp pathway in gizzard mesenchyme leads to a reduction of smooth muscle and mesenchymal thickness (Nielsen et al., 2001, Roberts et al., 1998, Smith et al., 2000). Additionally, elevated Bmp signaling leads to similar mesenchymal defects in the hindgut (De Santa Barbara et al., 2005). These results suggest that Bmp signaling, at least early on in mesenchymal development, may act as an inhibitor of smooth muscle growth.

A hallmark of SMCs is that they do not terminally differentiate but instead remain in a plastic state wherein they can switch between either a contractile and a synthetic/proliferative phenotype (Gabella, 2002). Bmp signaling also seems to play important roles in this later process of smooth muscle maturation toward the contractile phenotype. Misexpression of Rbpms2, an RNA binding protein expressed in visceral smooth muscle, hinders SMC differentiation into the contractile phenotype, as seen by a loss of Calponin expression (Notarnicola et al., 2012). This phenotype appears to be the direct result of an interaction between Rbpms2 and the Bmp antagonist Noggin, whereby Rbpms2 misexpression leads to the upregulation of the Noggin, loss of contractility, and increase in proliferation - resembling a more immature state. This can be at least partially phenocopied by the misexpression of Noggin, which leads to a downregulation of contractile genes and a concomitant upregulation of immature SMC markers such as Serum response factor and $\alpha$ SMA (Notarnicola et al., 2012, Sagnol et al., 2014). Thus, the outputs of Bmp signaling activity may be spatially and temporally dependent, perhaps hindering early muscle differentiation but later promoting its maturation.

\section{Interstitial cells and longitudinal muscle}

Significantly less is known about what controls the timing and location of longitudinal muscle layer differentiation. Data from both chick and mouse suggest the existence of a bipotent progenitor population of mesenchymal cells marked by c-kit expression that can give rise to either Interstitial Cells of Cajal (ICC) or longitudinal SMCs (Gabella, 2002, Kurahashi et al., 2008, Torihashi et al., 1999, Young, 2008). ICCs are the pacemaker cells that coordinate muscle contractions and are located neighboring muscle cells and neurons of the myenteric plexus or deep muscle plexus (Gabella, 1989, Gabella, 2002, Lecoin et al., 1996). Addition of neutralizing antibodies directed against c-kit perturb intestinal motility postnatally and lead to a loss of ICCs and a gain of longitudinal SMCs (Maeda et al., 1992, Torihashi et al., 1999). Conversely, inhibition of Pdgf signaling results in a gain of ICCs at the expense of smooth muscle (Kurahashi et al., 2008, Shyer et al., 2013). However, since Pdgf signaling is also required for differentiation of the first smooth muscle layer, it is more likely that Pdgf signaling plays a more general role in smooth muscle development. Thus it remains to be determined first what prevents the outer mesenchyme from differentiating concomitant with the first layer of muscle, and second what then instructs it to form at the appropriate time. One intriguing possibility is that a to-be-determined factor expressed in the mesothelium carries out this task (Thomason et al., 2012). 
Moving forward, it will be of general interest to decipher how these various aforementioned signaling pathways, as well as others, are integrated and whether a common, general mechanism is utilized along the length of the gut to pattern its discrete smooth muscle layers. Pointing to the possibility of compartment specific pathways, a study in mouse found that Nkx2.5 and Gata3 were required for longitudinal muscle formation specifically in the pylorus (Udager et al., 2014). An additional unresearched issue concerns the origin of the cells that form the longitudinal muscle layers. As opposed to forming from undifferentiated mesenchyme (as presented in the foregoing discussion), it has additionally been hypothesized that some longitudinal SMCs arise from cells of the circumferential layer that migrate radially and turn at right angles (Masumoto et al., 2000). Indeed, reorientation of smooth muscle occurs in the development of the mouse esophagus, albeit within the same layer (Romer et al., 2013). Live imaging of muscle differentiation in explant culture may resolve our understanding of how these layers arise and align during development.

\section{On cell alignment}

The alignment of SMCs is highly stereotyped and functionally important for morphogenesis and peristalsis. Few reports have addressed the mechanisms controlling the process of cell alignment in the digestive tract, let alone any visceral organ. For example, in the mouse ureter, which is also surrounded by smooth muscle, loss of Dlgh1 causes the circumferential layer to become longitudinally aligned (Mahoney et al., 2006). In blood vessels, vascular SMCs are known to realign during development (Greif et al., 2012), and this process is defective when ECM remodeling is perturbed (Nandadasa et al., 2015). Still, how these genes modulate signaling pathways or mechanical properties of the tissue to coordinate cell orientation is unknown. That the muscle layers of the gut arise at distinct times during development suggests that they can be exposed to different mechanical cues or molecular signals at their times of differentiation. Indeed, Coulombre and Coulombre (1958) proposed the possibility that the formation of the first circumferential layer initiates a period of intestinal elongation that may guide the outer mesenchyme to align longitudinally. A role for contact guidance and mechanical influence on smooth muscle orientation has been well studied in vitro (Tamiello et al., 2016), and thus it will be interesting to see if some of the same principles are acting to align muscle in the context of a growing organ. For example, concomitant with smooth muscle differentiation mesenchymal cells are producing extracellular matrix (Chevalier et al., 2016, Nagy et al., 2016), which could in theory provide a scaffold for cell alignment. On the other hand, cultured SMCs demonstrate the ability to form clumps of cells featuring two layers oriented perpendicular to one another, similar to the in vivo situation, indicating that the cells have the natural tendency to form at orthogonal angles without external cues (Chamley-Campbell et al., 1979). Traction forces have also been suggested to play a role in the alignment of connective tissue and muscle (Stopak and Harris, 1982). Finally, the migration of neural crest cells seems like a good candidate for a migratory population that, through its movement, could influence the morphology of surrounding cells. However, smooth muscle forms appropriately in the absence of neural crest cells, suggesting that they are not critical for this process (Graham et al., 2017, Smith et al., 1977), but, to our knowledge the alignment has not been carefully examined in the aneural scenario.

\section{Neural crest cells and muscle}

The layers of muscle are innervated by enteric neurons that are required to coordinate the peristaltic contractions that direct intestinal transit, and the avian embryo was paramount to identifying the origins of the enteric nervous system. Ablation, transplantation, and lineage tracing studies demonstrated that vagal neural crest largely residing between somites 1 through 7 migrate in a proximal-to-distal wave along the gut and give rise to the majority of the enteric nervous system (Allan and Newgreen, 1980, Le Douarin and Teillet, 1973, Yntema and Hammond, 1954). In addition, a second population of sacral crest cells in the posterior of the embryo populates the post umbilical gut in a distal-to-proximal manner (Burns and Douarin, 1998, Le Douarin and Teillet, 1973). These sacral cells have the ability to colonize an aganglionic hindgut that lacks vagal crest, but do not compensate for the lack of vagal crest (Burns et al., 2000). The migratory processes as well as patterning of the neural crest have been reviewed in detail elsewhere (Goldstein et al., 2013, Goldstein and Nagy, 2008, Hao et al., 2016, Heanue et al., 2016).

Ultimately, the neural crest cells organize and differentiate into two plexuses that flank the circumferential layer of muscle, separating it from the two longitudinal layers (Fig. 3). The timing and location of enteric neural crest differentiation implicates a possible influence on the adjacent smooth muscle layers, which form concurrently. When neural crest cells are ablated, smooth muscle differentiation in the gizzard is impaired due to upregulated Notch signaling, indicating a positive influence of the neural crest on smooth muscle differentiation (Faure et al., 2015). On the other hand, smooth muscle pattern is grossly unaltered in CAM-cultured aneural hindguts (Graham et al., 2017, Nagy et al., 2007). Therefore, there may be compartment-specific dependencies of smooth muscle differentiation on the neural crest. Consistent with this idea, hindgut smooth muscle differentiation occurs prior to the arrival of neural crest cells, whereas the foregut is colonized concomitant with smooth muscle differentiation (Bourret et al., 2017, Faure et al., 2015). It is important to note that the same signaling pathways, $\mathrm{Hh}$ and $\mathrm{Bmp}$, that pattern the smooth muscle also pattern the enteric nervous system. In addition, the smooth muscle itself seems to be important for ENS patterning in the midgut, as inhibition of circumferential layer differentiation in that compartment results in mislocalized crest cells and neurons (Graham et al., 2017). Whether this interaction is mediated by signals from the muscle or a mechanical environment provided by the muscle is to be determined. Since signals from the smooth muscle, endoderm, and neural crest cells themselves modulate ECM composition, it will be worthwhile to investigate how the ECM itself impacts differentiation and patterning of the mesenchyme and endoderm (Chevalier et al., 2016, Nagy et al., 2016). Work in the murine system has begun to address various roles of the basement membrane in muscle patterning and luminal buckling (Bolcato-Bellemin et al., 2003, Mahoney et al., 2008), but the avian embryo may provide a particularly good system to investigate this through, for example, misexpression of various matrix remodeling factors.

\section{Concluding thoughts}

Morphogenesis of the digestive tract is a complex process that involves molecular and mechanical interactions between all 
germ layers. How genetic determinants influence mechanical forces is an area of ongoing investigation, but presents its own challenges. The pleiotropic effects of the signal pathways acting within the gut tube often results in the simultaneous modulation of molecular, cellular, and tissue properties. For instance, alterations to the Hedgehog or BMP pathways in the developing gut affect smooth muscle differentiation and extracellular matrix composition (changing tissue stiffness) and additionally changes rates of cellular proliferation (changing tissue geometry) (Nagy et al., 2016, Nerurkar et al., 2017, Shyer et al., 2015, Shyer et al., 2013, Walton et al., 2012). Moving forward, it will be important to parse out how each of the properties is precisely regulated and contributes to the final size and shape of the gut. Likewise, it will be important to further elucidate how tissue mechanics feedback on gene regulation (Miller and Davidson, 2013). Folding of the intestinal lumen, for example, distorts morphogen gradients to alter downstream gene expression, but it is an open question if and how mechanical forces such as tissue stiffness or muscle contractions are sensed directly through mechanotransduction by cells within the gut to influence their morphology or differentiation.

The guiding principles of intestinal elongation have yet to be fully elucidated (Walton et al., 2016a). While intestinal growth is undoubtedly dependent upon proliferation, and defects in intestinal length correlate with changes in rates of proliferation, how proliferation itself can drive axially biased growth is unknown. Another question this raises is how mesoderm growth is coupled with that of the endoderm so that the process results in concerted elongation of the gut tube. While the gut mesenchyme appears mostly disorganized, the muscle layers display clear long axes that likely control their division orientations (Gabella, 2002, Gillies and Cabernard, 2011). Perhaps the smooth muscle itself also plays a mechanical role in orienting mesenchymal growth. Coulombre and Coulumbre (1958) originally postulated that the contraction of the circumferential smooth muscle once formed may drive the elongation process of the small intestine - constraining growth circumferentially and forcing longitudinal growth. Indeed, it has been noted that rapid increases in intestinal length are coupled with decreased growth in diameter, and conversely when diameter is increasing there is a coordinate decrease in lengthening (Coulombre and Coulombre, 1958, Thomason et al., 2012). Moreover, when the muscle is relaxed the intestine dramatically shortens in length (Chevalier et al., 2017). Thus, it seems likely that the force generated by the muscle alone is sufficient to induce a temporary tissue-wide elongation. While the small intestine undergoes dramatic elongation, other compartments of the digestive tract, such as the gizzard and large intestine, do not elongate as dramatically in length, and instead grow in thickness. Therefore, taking a comparative approach to study the elongation in each compartment may help elucidate the mechanisms that control axial growth. Given that the gut tube is regionally compartmentalized along the proximal distal axis early in development, it is likely the molecular mechanisms underlying the differential growth are determined early on. Evidence from gain and loss of function studies in both chick and mouse indeed show that longitudinal and radial growth can be genetically uncoupled (Cervantes et al., 2009, Geske et al., 2008, Nerurkar et al., 2017).

Smooth muscle cells are connected via gap junctions, which propagate the contractile wave through calcium transients. These calcium transients drive spontaneous, myogenic contractions be- ginning at E6, as soon as the first layer of circumferential muscle forms (Chevalier et al., 2017). The fact that aneural CAM cultured hindguts as well as explanted guts treated with the neurotoxin tetrodotoxin show contractile activity suggests that these embryonic contractions are myogenic and non-neurally mediated. When explants are cultured in media lacking calcium, contractions cease to occur, the smooth muscle relaxes, and the midgut concomitantly decreases in length while increasing in diameter (Chevalier et al., 2017). Results from mouse studies have indicated a similar mechanism whereby contractions of the digestive tract in the embryo are myogenic, and are not mediated by neurons or ICCs (Roberts et al., 2010). This raises the question of whether there is a functional or morphological purpose for these contractions in the embryo. Similar embryonic contractions have also been characterized in the fetal lung, propelling liquid through and potentially directing lung growth (Nakamura and McCray, 2000) (Bokka et al., 2015). How these myogenic contractions are initiated by the smooth muscle in the intestine is still to be determined, but the contraction of the cell is calcium dependent and thus modulators of calcium signaling are likely factors. Recent work in mouse has also shown the transient presence of spontaneous calcium waves in enteric neural crest cells as they are differentiating into enteric neurons, some of which are coordinated with muscle contractions (Hao 2107). It is likely that these are also present in chick, and it will be interesting to see how they coordinate with the spontaneous calcium waves of enteric neural crest cells, and furthermore how each of these influence differentiation and morphogenesis of the developing digestive tract.

It is intriguing to draw parallels between the patterning of the digestive tract with that of other tubular organs such as the ureter (Bohnenpoll and Kispert, 2014, Yu et al., 2002). Both systems are patterned by coupled $\mathrm{Hh}$ and $\mathrm{Bmp}$ signaling, with epithelial derived Hh driving expression of downstream targets such as Bmp4 in the subjacent mesenchyme and patterning layers of circumferential and longitudinal smooth muscle. In the ureter, Bmp4 is an agonist of muscle differentiation, whereas when misexpressed in the gizzard it decreases muscle thickness. Bmp signaling seems to act at multiple stages of smooth muscle maturation, and there may also be context dependent consequences of Bmp activity. For example, the ureteral mesenchyme is composed of intermediate mesoderm as opposed to splanchnic mesoderm of the gut. Intriguingly, the ureter also displays both inner circumferential and outer longitudinal muscle layers, implicating perhaps a general mechanism for developing cellular orientation. Moving forward, looking not only across species, but among other organs that share similar geometries may be informative in discovering general principles guiding their formation.

Finally, it will be important to uncover whether the same guiding genetic and mechanical determinants control morphogenesis of intestinal organoids, which can be grown to develop radial pattern and luminal morphology that highly replicates their in vivo counterparts (Watson et al., 2014, Workman et al., 2017). Because organoids can be derived from human induced pluripotent stem cells, studying their morphogenesis and function will contribute to our understanding of human gastrointestinal development and disease. Combining these new approaches with our growing understanding of gut morphogenesis obtained from the chick and other model systems may aid in our endeavors toward the regenerative purposes of bioengineering a functional human gut. 


\section{References}

ALLAN, I.J. and NEWGREEN, D.F. (1980). The origin and differentiation of enteric neurons of the intestine of the fowl embryo. Am J Anat 157: 137-154.

BALBI, V. and CIARLETTA, P. (2013). Morpho-elasticity of intestinal villi. J R Soc Interface 10: 20130109.

BALBI, V., KUHL, E. and CIARLETTA, P. (2015). Morphoelastic control of gastrointestinal organogenesis: Theoretical predictions and numerical insights. J. Mech. Phys. Soil. 78: 493-510.

BARKER, N., VAN ES, J.H., KUIPERS, J., KUJALA, P., VAN DEN BORN, M., COZIJNSEN, M., HAEGEBARTH, A., KORVING, J., BEGTHEL, H., PETERS, P.J. et al., (2007). Identification of stem cells in small intestine and colon by marker gene Lgr5. Nature 449: 1003-1007.

BELL, L. and WILLIAMS, L. (1982). Ascanning and transmission electron microscopical study of the morphogenesis of human colonic villi. Anat Embryol(Berl) 165:437-455.

BEN AMAR, M. and JIA, F. (2013). Anisotropic growth shapes intestinal tissues during embryogenesis. Proc Natl Acad Sci USA 110: 10525-10530.

BOHNENPOLL, T. and KISPERT, A. (2014). Ureter growth and differentiation. Semin Cell Dev Biol 36: 21-30.

BOKKA, K.K., JESUDASON, E.C., LOZOYA, O.A., GUILAK, F., WARBURTON, D. and LUBKIN, S.R. (2015). Morphogenetic Implications of Peristalsis-Driven Fluid Flow in the Embryonic Lung. PLoS One 10: e0132015.

BOLCATO-BELLEMIN, A.-L., LEFEBVRE, O., ARNOLD, C., SOROKIN, L., MINER, J.H., KEDINGER, M. and SIMON-ASSMANN, P. (2003). Laminin $\alpha 5$ chain is required for intestinal smooth muscle development. Dev. Biol. 260: 376-390.

BOURRET, A., CHAUVET, N., DE SANTA BARBARA, P. and FAURE, S. (2017). Colonic mesenchyme differentiates into smooth muscle before its colonization by vagal enteric neural crest-derived cells in the chick embryo. Cell Tissue Res 368: 503-511.

BURGESS, D.R. (1975). Morphogenesis of intestinal villi. II. Mechanism of formation of previllous ridges. J Embryol Exp Morphol 34: 723-740.

BURNS, A.J., CHAMPEVAL, D. and LE DOUARIN, N.M. (2000). Sacral neural crest cells colonise aganglionic hindgut in vivo but fail to compensate for lack of enteric ganglia. Dev Biol 219: 30-43.

BURNS, A.J. and DOUARIN, N.M. (1998). The sacral neural crest contributes neurons and glia to the post-umbilical gut: spatiotemporal analysis of the development of the enteric nervous system. Development 125: 4335-4347.

CERVANTES, S., YAMAGUCHI, T.P. and HEBROK, M. (2009). Wnt5a is essential for intestinal elongation in mice. Dev Biol 326: 285-294.

CHAMLEY-CAMPBELL, J., CAMPBELL, G.R. and ROSS, R. (1979). The smooth muscle cell in culture. Physiol Rev 59: 1-61.

CHEVALIER, N.R., FLEURY, V., DUFOUR, S., PROUX-GILLARDEAUX, V. and ASNACIOS, A. (2017). Emergence and development of gut motility in the chicken embryo. PLoS One 12: e0172511.

CHEVALIER, N.R., GAZGUEZ, E., BIDAULT, L., GUILBERT, T., VIAS, C., VIAN, E., WATANABE, Y., MULLER, L., GERMAIN, S., BONDURAND, N. et al., (2016). How Tissue Mechanical Properties Affect Enteric Neural Crest Cell Migration. Sci Rep 6: 20927.

CHIN, A.M., HILL, D.R., AURORA, M. and SPENCE, J.R. (2017). Morphogenesis and maturation of the embryonic and postnatal intestine. $066:$ 81-93.

CIARLETTA, P., BALBI, V. and KUHL, E. (2014). Pattern selection in growing tubular tissues. Phys Rev Lett 113: 248101

CLEVERS, H. (2013). The intestinal crypt, a prototype stem cell compartment. Cell 154: $274-284$

COULOMBRE, A.J. and COULOMBRE, J.L. (1958). Intestinal development. I. Morphogenesis of the villi and musculature. J Embryol Exp Morphol 6: 403-411.

CROSNIER, C., STAMATAKI, D. and LEWIS, J. (2006). Organizing cell renewal in the intestine: stem cells, signals and combinatorial control. Nat Rev Genet 7:349-359.

DAVIS, A., AMIN, N.M., JOHNSON, C., BAGLEY, K., GHASHGHAEI, H.T. and NASCONE-YODER, N. (2017). Stomach curvature is generated by left-right asymmetric gut morphogenesis. Development 144: 1477-1483.

DAVIS, N.M., KURPIOS, N.A., SUN, X., GROS, J., MARTIN, J.F. and TABIN, C.J. (2008). The chirality of gut rotation derives from left-right asymmetric changes in the architecture of the dorsal mesentery. Dev Cell 15: 134-145.
DE SANTA BARBARA, P., VAN DEN BRINK, G.R. and ROBERTS, D.J. (2003) Development and differentiation of the intestinal epithelium. Cell $\mathrm{Mol}$ Life $\mathrm{Sci}$ 60: 1322-1332.

DE SANTABARBARA, P., WILLIAMS, J., GOLDSTEIN, A.M., DOYLE, A.M., NIELSEN C., WINFIELD, S., FAURE, S. and ROBERTS, D.J. (2005). Bone morphogenetic protein signaling pathway plays multiple roles during gastrointestinal tract development. Dev Dyn 234: 312-322.

FAURE, S., MCKEY, J., SAGNOL, S. and DE SANTA BARBARA, P. (2015). Enteric neural crest cells regulate vertebrate stomach patterning and differentiation. Development 142: 331-342.

GABELLA, G. (1989). Development of smooth muscle: ultrastructural study of the chick embryo gizzard. Anat Embryol (Berl) 180: 213-226.

GABELLA, G. (2002). Development of visceral smooth muscle. Results Probl Cell Differ 38: 1-37.

GESKE, M.J., ZHANG, X., PATEL, K.K., ORNITZ, D.M. and STAPPENBECK, T.S. (2008). Fgf9 signaling regulates small intestinal elongation and mesenchymal development. Development 135: 2959-2968.

GILLIES, T.E. and CABERNARD, C. (2011). Cell division orientation in animals. Curr Biol 21: R599-R609.

GOLDSTEIN, A.M., HOFSTRA, R.M. and BURNS, A.J. (2013). Building a brain in the gut: development of the enteric nervous system. Clin Genet 83: 307-316.

GOLDSTEIN, A.M. and NAGY, N. (2008). A bird's eye view of enteric nervous system development: lessons from the avian embryo. Pediatr Res 64: 326-333.

GRAHAM, H.K., MAINA, I., GOLDSTEIN, A.M. and NAGY, N. (2017). Intestinal smooth muscle is required for patterning the enteric nervous system. JAnat 230: 567-574.

GREIF, D.M., KUMAR, M., LIGHTHOUSE, J.K., HUM, J., AN, A., DING, L., REDHORSE, K., ESPINOZA, F.H., OLSON, L., OFFERMANNS, S. et al., (2012). Radial construction of an arterial wall. Dev Cell 23: 482-493.

GREY, R.D. (1972). Morphogenesis of intestinal villi. I. Scanning electron microscopy of the duodenal epithelium of the developing chick embryo. J. Morphol. 137:193-213.

HAFFEN, K., LACROIX, B., KEDINGER, M. and SIMON-ASSMANN, P.M. (1982) Inductive Properties of Fibroblastic Cell Cultures Derived from Rat Intestinal Mucosa on Epithelial Differentiation*. Differentiation 23: 226-233.

HAO, M.M., FOONG, J.P., BORNSTEIN, J.C., LI, Z.L., VANDEN BERGHE, P. and BOESMANS, W. (2016). Enteric nervous system assembly: Functional integration within the developing gut. Dev Biol 417: 168-181.

HEANUE, T.A., SHEPHERD, I.T. and BURNS, A.J. (2016). Enteric nervous system development in avian and zebrafish models. Dev Biol 417: 129-138.

HILTON, W.A. (1902). The morphology and development of intestinal folds and Villi in vertibrates. Am. J. Anat. 1: 459-505.

JOHNSON, F.P. (1910). The development of the mucous membrane of the œsophagus, stomach and small intestine in the human embryo. Am. J. Anat. 10:521-575.

JOHNSON, F.P. (1913). The development of the mucous membrane of the large intestine and vermiform process in the human embryo. Am. J. Anat. 14: 187-233.

JOHNSON, F.P. (1914). The development of the rectum in the human embryo. Am. J. Anat. 16: 1-57.

KARLSSON, L., LINDAHL, P., HEATH, J.K. and BETSHOLTZ, C. (2000). Abnormal gastrointestinal development in PDGF-A and PDGFR-(alpha) deficient mice implicates a novel mesenchymal structure with putative instructive properties in villus morphogenesis. Development 127: 3457-3466.

KEDINGER, M., SIMON-ASSMANN, P., BOUZIGES, F., ARNOLD, C., ALEXANDRA E. and HAFFEN, K. (1990). Smooth muscle actin expression during rat gut development and induction in fetal skin fibroblastic cells associated with intestinal embryonic epithelium. Differentiation 43: 87-97.

KOYAMA, H., SHI, D., SUZUKI, M., UENO, N., UEMURA, T. and FUJIMORI, T. (2016). Mechanical Regulation of Three-Dimensional Epithelial Fold Pattern Formation in the Mouse Oviduct. Biophys J 111: 650-665.

KURAHASHI, M., NIWA, Y., CHENG, J., OHSAKI, Y., FUJITA, A., GOTO, H., FUJIMOTO, T. and TORIHASHI, S. (2008). Platelet-derived growth factor signals play critical roles in differentiation of longitudinal smooth muscle cells in mouse embryonic gut. Neurogastroenterol Motil 20: 521-531.

KURPIOS, N.A., IBANES, M., DAVIS, N.M., LUI, W., KATZ, T., MARTIN, J.F., IZPISUA BELMONTE, J.C. and TABIN, C.J. (2008). The direction of gut looping is established by changes in the extracellular matrix and in cell:cell adhesion. Proc Natl Acad Sci USA 105: 8499-8506. 
LACROIX, B., KEDINGER, M., SIMON-ASSMANN, P. and HAFFEN, K. (1984). Early organogenesis of human small intestine: scanning electron microscopy and brush border enzymology. Gut 25: 925-930.

LE DOUARIN, N.M. and TEILLET, M.A. (1973). The migration of neural crest cells to the wall of the digestive tract in avian embryo. J Embryol Exp Morphol 30: 31-48.

LE GUEN, L., MARCHAL, S., FAURE, S. and DE SANTA BARBARA, P. (2015). Mesenchymal-epithelial interactions during digestive tract development and epithelial stem cell regeneration. Cell Mol Life Sci 72: 3883-3896.

LECOIN, L., GABELLA, G. and LE DOUARIN, N. (1996). Origin of the c-kit-positive interstitial cells in the avian bowel. Development 122: 725-733.

LIM, S.-S. and LOW, F.N. (1988). Morphological changes in the developing alimentary canal: A review by scanning electron microscopy. In Ultrastructure of the Digestive Tract, (ed. Motta, P.M., Fujita, H. and Correr, S.). Springer US, Boston, MA, pp.1-16.

LYONS, K.M., PELTON, R.W. and HOGAN, B.L. (1990). Organogenesis and pattern formation in the mouse: RNA distribution patterns suggest a role for bone morphogenetic protein-2A (BMP-2A). Development 109: 833-844.

MAEDA, H., YAMAGATA, A., NISHIKAWA, S., YOSHINAGA, K., KOBAYASHI, S., NISHI, K. and NISHIKAWA, S. (1992). Requirement of c-kit for development of intestinal pacemaker system. Development 116: 369-375.

MAHADEVAN, A., WELSH, I.C., SIVAKUMAR, A., GLUDISH, D.W., SHILVOCK, A.R., NODEN, D.M., HUSS, D., LANSFORD, R. and KURPIOS, N.A. (2014). The leftright Pitx2 pathway drives organ-specific arterial and lymphatic development in the intestine. Dev Cell 31: 690-706.

MAHONEY, Z.X., SAMMUT, B., XAVIER, R.J., CUNNINGHAM, J., GO, G., BRIM, K.L., STAPPENBECK, T.S., MINER, J.H. and SWAT, W. (2006). Discs-large homolog 1 regulates smooth muscle orientation in the mouse ureter. Proc. Natl. Acad. Sci. USA 103: 19872-19877.

MAHONEY, Z.X., STAPPENBECK, T.S. and MINER, J.H. (2008). Laminin alpha 5 influences the architecture of the mouse small intestine mucosa. J Cell Sci 121: 2493-502.

MAO, J., KIM, B.M., RAJURKAR, M., SHIVDASANI, R.A. and MCMAHON, A.P. (2010). Hedgehog signaling controls mesenchymal growth in the developing mammalian digestive tract. Development 137: 1721-1729.

MASUMOTO, K., NADA, O., SUITA, S., TAGUCHI, T. and GUO, R. (2000). The formation of the chick ileal muscle layers as revealed by alpha-smooth muscle actin immunohistochemistry. Anat Embryol (Berl) 201: 121-129.

MCHUGH, K.M. (1995). Molecular analysis of smooth muscle development in the mouse. Dev Dyn 204: 278-290.

MCKEY, J., MARTIRE, D., DE SANTA BARBARA, P. and FAURE, S. (2016). LIX1 regulates YAP1 activity and controls the proliferation and differentiation of stomach mesenchymal progenitors. BMC Biol. 14: 34.

MCLIN, V.A., HENNING, S.J. and JAMRICH, M. (2009). The role of the visceral mesoderm in the development of the gastrointestinal tract. Gastroenterol.136: 2074-2091.

MILLER, C.J. and DAVIDSON, L.A. (2013). The interplay between cell signalling and mechanics in developmental processes. Nat Rev Genet 14: 733-744.

MITCHELL, P.C. (1896). 3. On the Intestinal Tract of Birds. Proc. Zool. Soc. Lon. 64: 136-159.

NAGY, N., BARAD, C., GRAHAM, H.K., HOTTA, R., CHENG, L.S., FEJSZAK, N and GOLDSTEIN, A.M. (2016). Sonic hedgehog controls enteric nervous system development by patterning the extracellular matrix. Development 143: 264-275.

NAGY, N., BREWER, K.C., MWIZERWA, O. and GOLDSTEIN, A.M. (2007). Pelvic plexus contributes ganglion cells to the hindgut enteric nervous system. Dev Dyn 236: 73-83.

NAKAMURA, K.T. and MCCRAY, P.B., JR. (2000). Fetal airway smooth-muscle contractility and lung development. A player in the band or just someone in the audience? Am J Respir Cell Mol Biol 23: 3-6.

NANDADASA, S., NELSON, C.M. and APTE, S.S. (2015). ADAMTS9-Mediated Extracellular Matrix Dynamics Regulates Umbilical Cord Vascular Smooth Muscle Differentiation and Rotation. Cell Rep 11: 1519-1528.

NARITA, T., ISHII, Y., NOHNO, T., NOJI, S. and YASUGI, S. (1998). Sonic hedgehog expression in developing chicken digestive organs is regulated by epithelialmesenchymal interactions. Dev Growth Differ 40: 67-74.

NERURKAR, N.L., MAHADEVAN, L. and TABIN, C.J. (2017). BMP signaling controls buckling forces to modulate looping morphogenesis of the gut. Proc Natl Acad
Sci USA 114: 2277-2282.

NIELSEN, C., MURTAUGH, L.C., CHYUNG, J.C., LASSAR, A. and ROBERTS, D.J. (2001). Gizzard formation and the role of Bapx1. Dev Biol 231: 164-174.

NOAH, T.K., DONAHUE, B. and SHROYER, N.F. (2011). Intestinal development and differentiation. Exp Cell Res 317: 2702-2710.

NOTARNICOLA, C., ROULEAU, C., LE GUEN, L., VIRSOLVY, A., RICHARD, S., FAURE, S. and DE SANTA BARBARA, P. (2012). The RNA-binding protein RBPMS2 regulates development of gastrointestinal smooth muscle. Gastroenterology 143: 687-97 e1-9.

ONOUCHI, S., ICHII, O., NAKAMURA, T., ELEWA, Y.H. and KON, Y. (2016). Spatiotemporal distribution of extracellular matrix changes during mouse duodenojejunal flexure formation. Cell Tissue Res 365: 367-379.

ONOUCHI, S., ICHII, O., OTSUKA-KANAZAWA, S. and KON, Y. (2015). Asymmetric morphology of the cells comprising the inner and outer bending sides of the murine duodenojejunal flexure. Cell Tissue Res 360: 273-285

ONOUCHI, S., ICHII, O., OTSUKA, S., HASHIMOTO, Y. and KON, Y. (2013). Analysis of duodenojejunal flexure formation in mice: implications for understanding the genetic basis for gastrointestinal morphology in mammals. J Anat 223: 385-398.

OVERTON, J. and SHOUP, J. (1964). Fine structure of cell surface specializations in the maturing duodenal mucosa of the chick. J Cell Biol 21: 75-85.

RAMALHO-SANTOS, M., MELTON, D.A. and MCMAHON, A.P. (2000). Hedgehog signals regulate multiple aspects of gastrointestinal development. Development 127: $2763-2772$

ROBERTS, D.J. (2000). Molecular mechanisms of development of the gastrointestinal tract. Dev Dyn 219: 109-120.

ROBERTS, D.J., JOHNSON, R.L., BURKE, A.C., NELSON, C.E., MORGAN, B.A. and TABIN, C. (1995). Sonic hedgehog is an endodermal signal inducing Bmp-4 and Hox genes during induction and regionalization of the chick hindgut. Development 121: 3163-3174.

ROBERTS, D.J., SMITH, D.M., GOFF, D.J. and TABIN, C.J. (1998). Epithelialmesenchymal signaling during the regionalization of the chick gut. Development 125: 2791-2801.

ROBERTS, R.R., ELLIS, M., GWYNNE, R.M., BERGNER, A.J., LEWIS, M.D., BECKETT, E.A., BORNSTEIN, J.C. and YOUNG, H.M. (2010). The first intestinal motility patterns in fetal mice are not mediated by neurons or interstitial cells of Cajal. J Physiol 588: 1153-1169.

ROMANOFF, A.L. (1960). The avian embryo. Structural and functional development New York and London: The Macmillan Co., New York.

ROMER, A.I., SINGH, J., RATTAN, S. and KRAUSS, R.S. (2013). Smooth muscle fascicular reorientation is required for esophageal morphogenesis and dependent on Cdo. J Cell Biol 201: 309-323.

RYAN, A.K., BLUMBERG, B., RODRIGUEZ-ESTEBAN, C., YONEI-TAMURA, S., TAMURA, K., TSUKUI, T., DE LA PENA, J., SABBAGH, W., GREENWALD, J., CHOE, S. et al., (1998). Pitx2 determines left-right asymmetry of internal organs in vertebrates. Nature 394: 545-551.

SAGNOL, S., YANG, Y., BESSIN, Y., ALLEMAND, F., HAPKOVA, I., NOTARNICOLA, C., GUICHOU, J.F., FAURE, S., LABESSE, G. and DE SANTA BARBARA, P. (2014). Homodimerization of RBPMS2 through a new RRM-interaction motif is necessary to control smooth muscle plasticity. Nucleic Acids Res 42: 10173-84.

SAVIN, T., KURPIOS, N.A., SHYER, A.E., FLORESCU, P., LIANG, H., MAHADEVAN, L. and TABIN, C.J. (2011). On the growth and form of the gut. Nature 476: 57-62.

SBARBATI, R. (1982). Morphogenesis of the intestinal villi of the mouse embryo: chance and spatial necessity. J Anat 135: 477-499.

SHYER, A.E., HUYCKE, T.R., LEE, C., MAHADEVAN, L. and TABIN, C.J. (2015) Bending gradients: how the intestinal stem cell gets its home. Cell 161: 569-580

SHYER, A.E., TALLINEN, T., NERURKAR, N.L., WEI, Z., GIL, E.S., KAPLAN, D.L., TABIN, C.J. and MAHADEVAN, L. (2013). Villification: how the gut gets its villi. Science 342: 212-218

SMITH, D.M., NIELSEN, C., TABIN, C.J. and ROBERTS, D.J. (2000). Roles of BMP signaling and $\mathrm{Nkx2.5}$ in patterning at the chick midgut-foregut boundary. Development 127: 3671-3681.

SMITH, J., COCHARD, P. and LE DOUARIN, N.M. (1977). Development of choline acetyltransferase and cholinesterase activities in enteric ganglia derives from presumptive adrenergic and cholinergic levels of the neural crest. Cell Differ 6 : $199-216$. 
SOFFERS, J.H., HIKSPOORS, J.P., MEKONEN, H.K., KOEHLER, S.E. and LAMERS, W.H. (2015). The growth pattern of the human intestine and its mesentery. BMC Dev Biol 15: 31

SOUTHWELL, B.R. (2006). Staging of intestinal development in the chick embryo. Anat Rec A Discov Mol Cell Evol Biol 288: 909-920.

SPENCE, J.R., LAUF, R. and SHROYER, N.F. (2011). Vertebrate intestinal endoderm development. Dev Dyn 240: 501-520.

STOPAK, D. and HARRIS, A.K. (1982). Connective tissue morphogenesis by fibroblast traction. I. Tissue culture observations. Dev Biol 90: 383-398.

SUKEGAWA, A., NARITA, T., KAMEDA, T., SAITOH, K., NOHNO, T., IBA, H., YASUGI, S. and FUKUDA, K. (2000). The concentric structure of the developing gut is regulated by Sonic hedgehog derived from endodermal epithelium. Development 127: 1971-1980.

TAMIELLO, C., BUSKERMOLEN, A.B., BAAIJENS, F.P., BROERS, J.L. and BOUTEN, C.V. (2016). Heading in the Right Direction: Understanding Cellular Orientation Responses to Complex Biophysical Environments. Cell Mol Bioeng 9: 12-37.

THOMASON, R.T., BADER, D.M. and WINTERS, N.I. (2012). Comprehensive timeline of mesodermal development in the quail small intestine. Dev Dyn241:1678-1694.

TORIHASHI, S., NISHI, K., TOKUTOMI, Y., NISHI, T., WARD, S. and SANDERS, K.M. (1999). Blockade of kit signaling induces transdifferentiation of interstitial cells of cajal to a smooth muscle phenotype. Gastroenterology 117: 140-148.

UDAGER, A.M., PRAKASH, A., SAENZ, D.A., SCHINKE, M., MORIGUCHI, T., JAY, P.Y., LIM, K.C., ENGEL, J.D. and GUMUCIO, D.L. (2014). Proper development of the outer longitudinal smooth muscle of the mouse pylorus requires Nkx2-5 and Gata3. Gastroenterology 146: 157-65.

WALLACE, K.N., AKHTER, S., SMITH, E.M., LORENT, K. and PACK, M. (2005). Intestinal growth and differentiation in zebrafish. Mech Dev 122: 157-173.

WALTON, K.D., FREDDO, A.M., WANG, S. and GUMUCIO, D.L. (2016a). Generation of intestinal surface: an absorbing tale. Development 143: 2261-2272.

WALTON, K.D., KOLTERUD, A., CZERWINSKI, M.J., BELL, M.J., PRAKASH, A., KUSHWAHA, J., GROSSE, A.S., SCHNELL, S. and GUMUCIO, D.L. (2012). Hedgehog-responsive mesenchymal clusters direct patterning and emergence of intestinal villi. Proc Natl Acad Sci USA 109: 15817-15822.
WALTON, K.D., WHIDDEN, M., KOLTERUD, A., SHOFFNER, S.K., CZERWINSKI, M.J., KUSHWAHA, J., PARMAR, N., CHANDHRASEKHAR, D., FREDDO, A.M., SCHNELL, S. et al., (2016b). Villification in the mouse: Bmp signals contro intestinal villus patterning. Development 143: 427-436.

WATSON, C.L., MAHE, M.M., MUNERA, J., HOWELL, J.C., SUNDARAM, N., POLING, H.M., SCHWEITZER, J.I., VALLANCE, J.E., MAYHEW, C.N., SUN, Y. et al., (2014). An in vivo model of human small intestine using pluripotent stem cells. Nat Med 20: 1310-1314.

WELLS, J.M. and SPENCE, J.R. (2014). How to make an intestine. Development 141: $752-760$.

WELSH, I.C., THOMSEN, M., GLUDISH, D.W., ALFONSO-PARRA, C., BAI, Y. MARTIN, J.F. and KURPIOS, N.A. (2013). Integration of left-right Pitx2 transcription and Wht signaling drives asymmetric gut morphogenesis via Daam2. Dev Cell 26: 629-644.

WOLFF, C.F. and DUPONT, J.C. (1768-1769). De Formatione Intestinorum. Brepols.

WORKMAN, M.J., MAHE, M.M., TRISNO, S., POLING, H.M., WATSON, C.L., SUNDARAM, N., CHANG, C.F., SCHIESSER, J., AUBERT, P., STANLEY, E.G. et al., (2017). Engineered human pluripotent-stem-cell-derived intestinal tissues with a functional enteric nervous system. Nat Med 23: 49-59.

YAMAMOTO, Y., KUBOTA, T., ATOJI, Y. and SUZUKI, Y. (1996). Distribution of alphavascular smooth muscle actin in the smooth muscle cells of the gastrointestinal tract of the chicken. J Anat 189 (Pt 3): 623-630.

YASUGI, S. and MIZUNO, T. (2008). Molecular analysis of endoderm regionalization Dev Growth Differ 50 Suppl 1: S79-S96.

YNTEMA, C.L. and HAMMOND, W.S. (1954). The origin of intrinsic ganglia of trunk viscera from vagal neural crest in the chick embryo. J Comp Neurol 101: 515-541.

YOUNG, H.M. (2008). On the outside looking in: longitudinal muscle development in the gut. Neurogastroenterol Motil 20: 431-433.

YU, J., CARROLL, T.J. and MCMAHON, A.P. (2002). Sonic hedgehog regulates proliferation and differentiation of mesenchymal cells in the mouse metanephric kidney. Development 129: 5301-5312.

ZACHARIAS, W.J., MADISON, B.B., KRETOVICH, K.E., WALTON, K.D., RICHARDS N., UDAGER, A.M., LI, X. and GUMUCIO, D.L. (2011). Hedgehog signaling controls homeostasis of adult intestinal smooth muscle. Dev Biol 355: 152-162. 


\section{Further Related Reading, published previously in the Int. J. Dev. Biol.}

Roles of DSCAM in axonal decussation and fasciculation of chick spinal interneurons Oksana Cohen, Lilach Vald, Masahito Yamagata, Joshua R. Sanes and Avihu Klar

Int. J. Dev. Biol. (2017) 61: 235-244

https://doi.org/10.1387/ijdb.160235ak

Developmental expression of chicken FOXN1 and putative target genes during feather development Diana K. Darnell, Li S. Zhang, Sridhar Hannenhalli and Sergey Y. Yaklichkin

Int. J. Dev. Biol. (2014) 58: 57-64

https://doi.org/10.1387/ijdb.130023sy

Differential expression of angiogenic and anti-angiogenic molecules in the chick embryo chorioallantoic membrane and selected organs during embryonic development

Christian Marinaccio, Beatrice Nico and Domenico Ribatti

Int. J. Dev. Biol. (2013) 57: 907-916

https://doi.org/10.1387/ijdb.130317dr

Lack of organ specific commitment of vagal neural crest cell derivatives as shown by back-transplantation of GFP chicken tissues

Lucy J. Freem, Jean Marie Delalande, Alison M. Campbell, Nikhil Thapar and Alan J. Burns Int. J. Dev. Biol. (2012) 56: 245-254

https://doi.org/10.1387/ijdb.113438lf

Decorin developmental expression and function in the early avian embryo

Nikolas Zagris, Konstantina Gilipathi, Nikolitsa Soulintzi and Konstantinos Konstantopoulos Int. J. Dev. Biol. (2011) 55: 633-639

https://doi.org/10.1387/ijdb.113321nz

Migration of neural crest-derived enteric nervous system precursor cells to and within the gastrointestinal tract

Alan J. Burns

Int. J. Dev. Biol. (2005) 49: 143-150

http://www.intjdevbiol.com/web/paper/041935ab

Molecular analysis of the determination of developmental fate in the small intestinal epithelium in the chicken embryo

Hiroaki Hiramatsu and Sadao Yasugi

Int. J. Dev. Biol. (2004) 48: 1141-1148

http://www.intjdevbiol.com/web/paper/041886hh

5 yr ISI Impact Factor $(2016)=2.421$
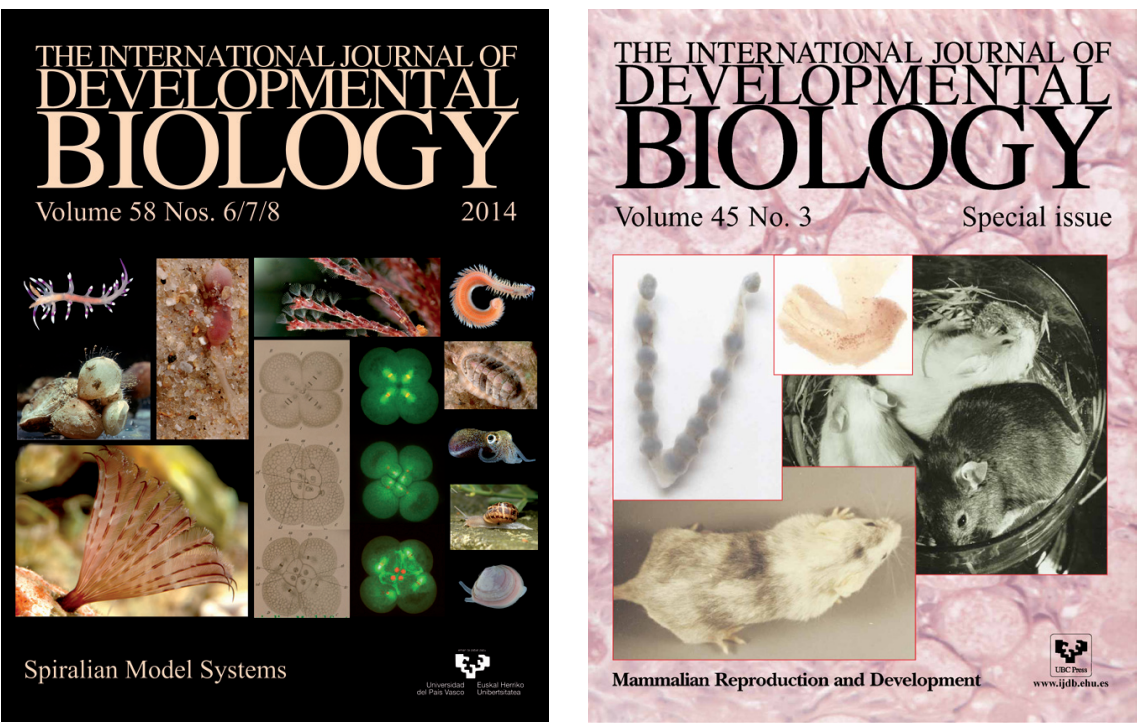
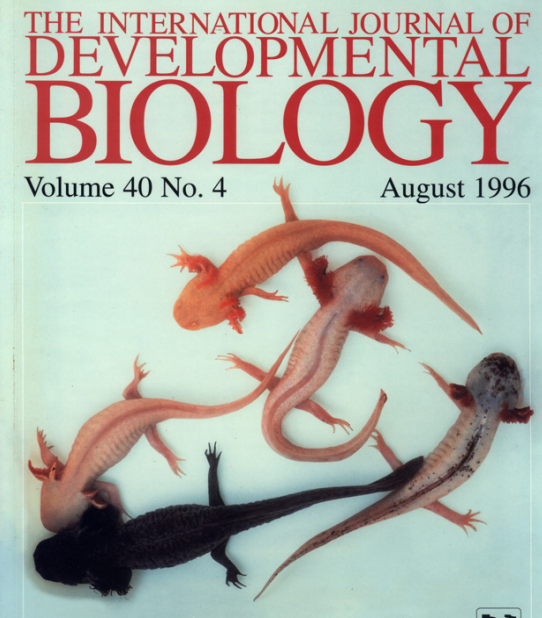

Developmental Biology of Urodeles

tiscos
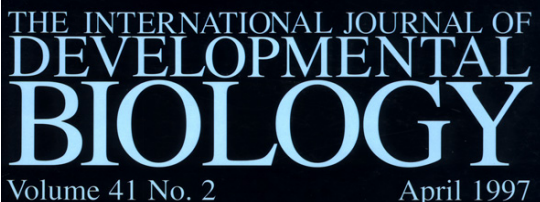

April 1997

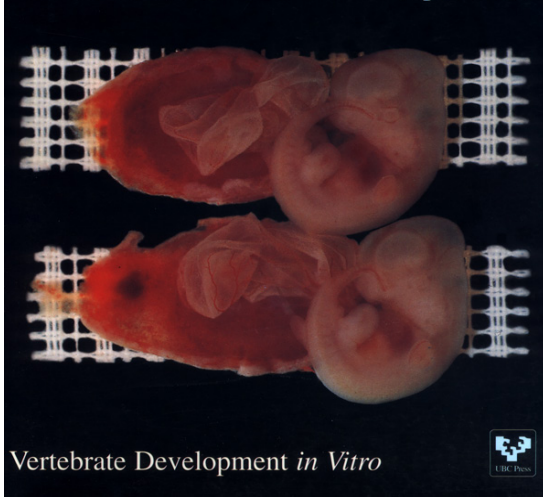

